\title{
Antiviral evaluation of an Hsp90 inhibitor, gedunin, against dengue virus
}

\author{
Deeba Amraiz, Najam-us-Sahar Sadaf Zaidi* and Munazza Fatima \\ Atta-ur-Rahman School of Applied Biosciences, National University of Sciences and Technology, Sector H-12, Islamabad, \\ Pakistan 44000 \\ *For correspondence: Email: zaidi.sahar@gmail.com; Tel: +92-51-9085-6132; Fax: +92-51-9085-6102
}

\begin{abstract}
Purpose: To evaluate the antiviral potential of a tetranortriterpenoid, gedunin, against dengue virus (DENV) replication by targeting the host chaperone, Hsp90.

Methods: The compound, gedunin, was tested against the replication of DENV in vitro using BHK-15 cells transfected with DENV-2 subgenomic replicon. Molecular docking of gedunin with Hsp90 protein was performed for evaluation of mode of action, using the program, Autodock vina.

Results: In vitro antiviral data showed that gedunin significantly $(p<0.05)$ reduced DENV replication with $E C_{50}$ of $10 \mu \mathrm{M}$. Further, in silico molecular docking data revealed strong interaction of gedunin with the ATP/ADP binding site of the host protein, Hsp90, with an estimated average free binding energy of $8.9 \mathrm{kcal} / \mathrm{mol}$.

Conclusion: The results validate gedunin as a potential antiviral candidate. Further in vitro assays and in vivo viral challenge studies are required to confirm the exact mode of action and pharmacological profile of gedunin in DENV infections.
\end{abstract}

Keywords: Dengue virus replication, Hsp90, Gedunin, Antiviral, Molecular docking

\begin{abstract}
Tropical Journal of Pharmaceutical Research is indexed by Science Citation Index (SciSearch), Scopus, International Pharmaceutical Abstract, Chemical Abstracts, Embase, Index Copernicus, EBSCO, African Index Medicus, JournalSeek, Journal Citation Reports/Science Edition, Directory of Open Access Journals (DOAJ), African Journal Online, Bioline International, Open-J-Gate and Pharmacy Abstracts
\end{abstract}

\section{INTRODUCTION}

Dengue virus belongs to the family Flaviviridae and has recently emerged as a significant human pathogen causing 50-100 million infections per year globally [1]. Due to complexity of the immune response towards vaccines and the need to control the four virus serotypes simultaneously, the development of vaccines has been challenging [2]. Several studies have previously suggested that both viral and host proteins essential for viral replication can be exploited for antiviral development [1]. Like many cellular proteins, the viral proteins also require host chaperones as support for proper functions [3]. Hsp90 is an ATP dependent heat shock protein, which is highly conserved among many species from yeast to humans and involved in the regulation of several signaling, oncogenic and cell cycle protein $[4,5]$. The dependence of several oncogenes and other signaling processes involved in cancer progression on Hsp90 makes it a potential target against cancers [6,7]. It was shown that gedunin as an anticancer agent inhibits the function of Hsp90 protein, resulting in the degradation and improper functioning of the client proteins, similar to other Hsp90 inhibitors [8]. Numerous Hsp90 inhibitors, identified as anticancer agents such as radicicol, geldanamycin (GA), and GA derivatives, block Hsp90 activity by binding to the N-terminal ATP pocket of the protein and inhibiting ATPase activity [9]. Geldanamycin was shown to be active against replication of a range of viruses, 
including herpes simplex virus type 1 (HSV-1), severe acute respiratory syndrome coronavirus and Zaire EBOV in vitro $[10,11]$.

It has been observed for several viruses, including Ebola, Influenza, DENV, and Japanese encephalitis virus (JEV), that many proteins of these viruses require Hsp90 for their folding, assembly, and maturation, making it an attractive target for antiviral development [3]. Other studies have suggested that Hsp90 also binds to the viral components mainly to the RNA polymerase affecting the assembly and nuclear transport of polymerase [12]. Researchers have found a tetranortriterpenoid compound called gedunin, obtained from the Indian neem tree (Azadirachta indica), to be active against the $90 \mathrm{kDa} H s p 90$ by binding directly to its helper protein p23 leading to its inactivation $[13,14]$. Neem has been found to possess antiviral activity against DENV, Ebola virus and coxsackie $B$ virus, a group of enteroviruses [15]. Furthermore, in vitro studies and high throughput assays with gedunin and gedunin derivatives confirmed that these compounds inhibit Ebola virus replication and protein expression as well as their host cell binding [16]. However, the mechanism by which gedunin disrupts the function of Hsp90 or its client proteins consequently leading to reduction of viral replication in cell cultures, is still not completely understood. This study was conducted to evaluate the inhibitory potential of gedunin against DENV-2 replicon in cell culture. Further, molecular docking was performed in order to investigate the possible interaction of gedunin with Hsp90. The results of this study will aid in the development of more effective therapeutics to treat dengue virus infections.

\section{EXPERIMENTAL}

\section{Cell culture, replicon construct and test compound}

BHK-15 cells were grown in minimal essential medium (MEM) containing $10 \%$ fetal bovine serum (FBS) at $37^{\circ} \mathrm{C}$ incubator in the presence of $5 \% \mathrm{CO}_{2}$. DENV-2 replicon containing the nonstructural genes and $R$. luciferase as a reporter was used for the replicon assays to test the compound against dengue replication. The replicon construct and the compound were obtained from the Department of Biological Sciences, Purdue University, Indiana, USA. The test compound, gedunin, was suspended in DMSO and four dilutions (1, 10, 50 and $100 \mu \mathrm{M})$ of the compound based on the efficacy of these concentrations were tested against DENV replicon in vitro in BHK cells.

\section{RNA transcription and electroporation}

E. coli DH5- $\alpha$ cells were transformed with DENV2-R.luc-Rep, transformed colonies were inoculated in LB media containing $100 \mu \mathrm{g}$ ampicillin overnight in a $37^{\circ} \mathrm{C}$ shaking incubator. Plasmid DNA was purified using midiprep (Qiagen) kit and linearized by Xba-I digestion. Linearized DNA was purified with GFx columns and used as template for in vitro transcription using T7 RNA polymerase. Replicon RNA was purified with the RNeasy kit (Qiagen).

For RNA electroporation, $2 \times 10^{6}$ BHK cells were washed twice before being resuspended in 0.4 $\mathrm{ml}$ of room temperature PBS containing $10-20$ $\mu \mathrm{g}$ of RNA. The cells were pulsed twice consecutively, using the electroporation apparatus (BioRad Gene-Pulser II), at $25 \mu \mathrm{F}, 1.5$ $\mathrm{kV}$, and $200 \mathrm{Ohms}$ in a $0.2 \mathrm{~cm}$ cuvette. Electroporated cells were incubated at room temperature for $3 \mathrm{~min}$ and $1 \mathrm{~mL}$ of $2.5 \%$ FBSMEM was added to the cells. Cells were resuspended and the contents of the cuvette were then transferred to $9 \mathrm{~mL}$ of $2.5 \%$ FBSMEM. The cells were mixed well, plated into a 96-well plate $(100 \mu \mathrm{l}$ per well) and incubated in a $5 \% \mathrm{CO}_{2}$ incubator for $2 \mathrm{~h}$ at $37^{\circ} \mathrm{C}$.

\section{Compound treatment}

After $2 \mathrm{~h}$ of incubation, media was aspirated off from the electroporated cells in a 96 wells plate and drug dilutions were added at final concentrations of $1,10,50$ and $100 \mu \mathrm{M}$ in $2.5 \%$ FBS-MEM, while $1 \%$ DMSO and untreated cells were used as negative controls. Three replicates were used for each dilution. Cells were grown at $37^{\circ} \mathrm{C}$ for $48 \mathrm{~h}$ in $5 \% \mathrm{CO}_{2}$ incubator.

\section{Luciferase assay}

The cell extracts were taken at $48 \mathrm{~h}$ postinfection, washed with PBS and then lysed with Renilla luciferase lysis buffer. These cells were incubated at room temperature for $30 \mathrm{~min}$ with gentle rocking and stored at $-80{ }^{\circ} \mathrm{C}$ till further use. Luciferase activity was measured using standard Promega's Renilla luciferase assay system. The frozen extracts (lysates) were thawed and then homogenized by gentle pipetting. For the luciferase activity, $10 \mu \mathrm{L}$ of lysate from each well was transferred to an opaque plate. Luminescence was then measured after adding $50 \mu \mathrm{L}$ of luciferase substrate to the cells using SpectraMaxL microplate reader (SoftMax Pro 5.4.4 software, Molecular Devices) and activity was detected in relative light units (RLU). 


\section{Cytotoxicity assay}

BHK-15 cells at $90 \%$ confluence were treated with gedunin, diluted in $2 \%$ FBS-MEM, for the same range of concentrations as used for replicon assays in a 96-well plate, and incubated at $37{ }^{\circ} \mathrm{C}$ in the presence of $5 \% \mathrm{CO}_{2}$. At $48 \mathrm{~h}$ post-treatment, the compound dilutions were aspirated from the cells, and washed with MEM. Cell toxicity of the compound was then measured using Quick Cell Proliferation Assay kit. Substrate from the kit was diluted appropriately and $100 \mu \mathrm{L}$ of the substrate was added to each well. Plate was then incubated at $37^{\circ} \mathrm{C}$ for $2 \mathrm{~h}$ and the optical density $\left(\mathrm{OD}_{450}\right)$ was measured using a microplate reader, SpectraMax M5 (SoftMax Pro 4.8 software, Molecular Devices). The $\mathrm{OD}_{450}$ obtained for cells treated with the drug dilutions were compared to the cells treated with $1 \%$ DMSO alone as negative control.

\section{Molecular docking studies}

\section{Preparation of ligand}

Chemical structure of gedunin was obtained from PubChem chemistry database, which has been reported to inhibit Hsp90 protein [8]. The structure of the compound was then drawn in ChemSketch software 11.02 (Advanced Chemistry Development, Inc. ACD/Labs) and 3-D structure optimization was done by adding hydrogen atoms to the ligand. The refined structure was saved in .mol format and then converted to pdb file format using ArgusLab 4.0.1 (Mark Thompson and Planaria Software LLC). Then torsions of the ligand were stabilized, nonpolar hydrogens were added and PDBQT file was prepared using AutoDock Tool for further analysis through molecular docking.

\section{Preparation of Hsp90 as a target protein}

The structure of Hsp90 in complex with ADP in the N-terminal ADP/ATP binding site (PDB ID: 1AM1) was retrieved from RSCB Protein Data Bank [17]. Ligand molecule was initially removed for the purpose of docking. The protein structure was adjusted and optimized by adding hydrogen atoms and removing water molecules using AutoDockTools 1.5.6 (The Scripps Research Institute, La Jolla, USA). The grid box for the receptor was then set to cover the entire molecular surface and the output file was generated in PDBQT format.

\section{Molecular docking}

Molecular docking was then initiated using AutoDock Vina 1.1.2 [18] and the predicted binding affinity of the ligand with the receptor was calculated based on the scoring function in $\mathrm{kcal} / \mathrm{mol}$. After docking, the docked complex having a conformation with the lowest binding affinity value was selected and saved in pdb format. The docked complexes were analyzed using UCSF Chimera version 1.8.1 (Resource for Biocomputing, Visualization, and Informatics at the University of California, San Francisco). Twodimensional and three-dimensional interaction patterns of the docked complex were determined in order to study the amino acids involved in the ligand-protein binding site using Discovery Studio (Version 4.1.0).

\section{Statistical analysis}

The RLU values from the luciferase assay were plotted against the log transformation of the compound concentrations and the effective concentration $\left(\mathrm{EC}_{50}\right)$ was determined using GraphPad Prism version 5 software (GraphPad Software, San Diego California, USA). Data are presented as mean \pm standard deviation (SD, $n=$ 3). The data were evaluated statistically using one-way analysis of variance (ANOVA) and $p<$ 0.05 was considered significant.

\section{RESULTS}

\section{Inhibition of dengue virus subgenomic replicon in cell culture}

The inhibitory activity of gedunin was evaluated against DENV replication in a replicon based assay. Here, four different dilutions of the compound $(1,10,50$ and $100 \mu \mathrm{M})$ were tested against dengue virus replication using the DENV replicon containing the reporter gene $(R$. luciferase), while DMSO (1\%) treated cells were used as negative control in the inhibition assays. Luciferase assays were performed with the cell extracts using standard $R$. luciferase substrate. Cells treated with $1 \%$ DMSO were used as negative control for inhibition. The relative light units (RLU) were plotted against the log transformation of the concentrations of the compound and a concentration dependent virus inhibition was observed (Figure 1). Upon an increase in the concentration of gedunin, a significant reduction of reporter activity was observed and almost complete inhibition was observed at higher concentrations such as 50 and $100 \mu \mathrm{M}$. $E_{50}$ value was determined using GraphPad Prism software. Gedunin exhibited significant reduction in the luciferase activity compared with the control indicating the inhibition of genome replication with $\mathrm{EC}_{50}$ of $10 \mu \mathrm{M}$. 


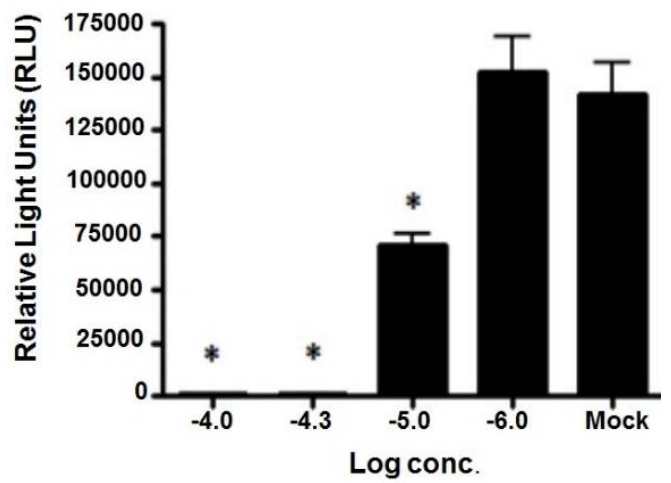

Figure 1: Inhibitory activity of gedunin against DENV-R.luc2A-RP replicon. Test concentrations indicating significant inhibition are represented by asterisk; ${ }^{*} p<0.05$ using one way ANOVA). Mock indicates treatment with $1 \%$ dimethyl sulfoxide; $\mathrm{n}$ $=3$; error bars indicate standard deviation

Each of these compound concentrations were then tested for cytotoxicity in BHK-15 cells at 90 $\%$ confluence using the quick cell proliferation assay. Cytotoxicity assays were also performed for each concentration in a 96 well format and optical densities were determined at $450 \mathrm{~nm}$ using micro-titer plate reader. The optical densities obtained with the drugs were compared with that of the DMSO treated and untreated cells and there was no toxicity observed within the range of the concentrations used up to 100 $\mu \mathrm{M}$.

\section{Gedunin-Hsp90 docking results}

Gedunin was selected as the ligand for this study on the basis of its previous roles in modulation of the Hsp90 activity in cancers and antiviral studies. Structures of gedunin (Figure 2) and Hsp90 (PDB: 1AM1, Figure 3) were processed for computational analysis using AutoDock Tool, then gedunin was docked withHsp90 at its Nterminal binding pocket using AutoDock vina.

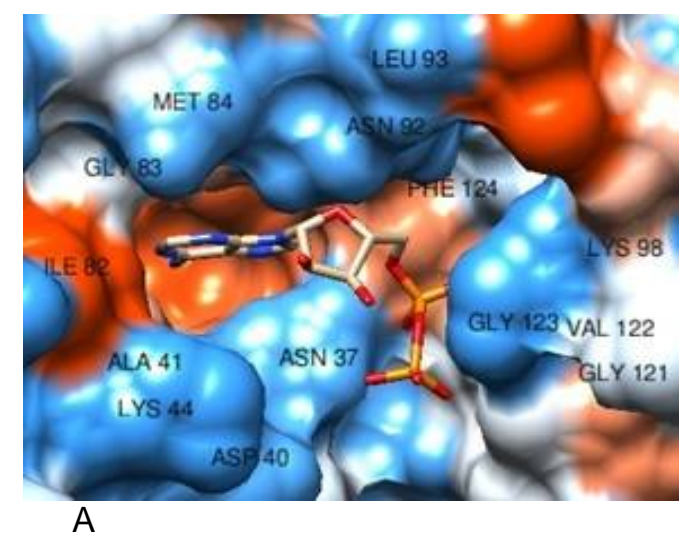

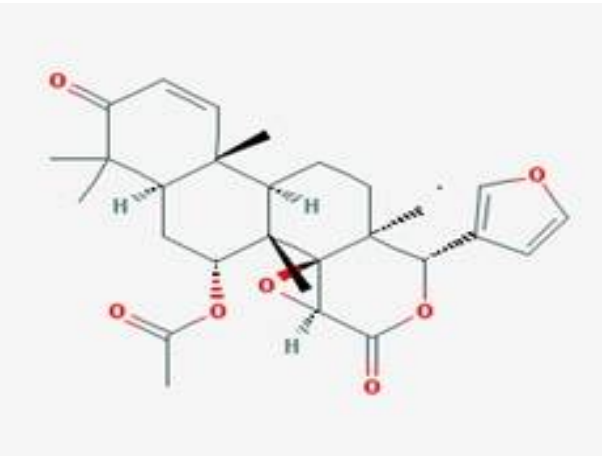

Figure 2: Structure of gedunin

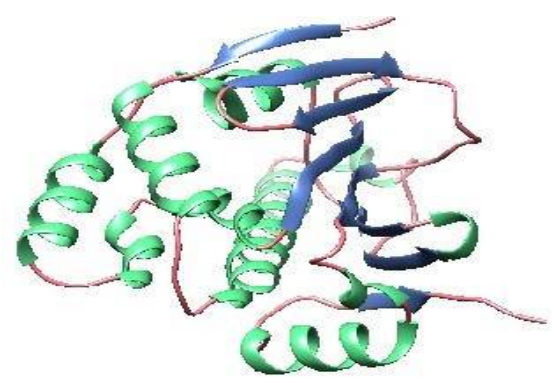

Figure 3: Crystal structure of Hsp90 (PDB 1AM1)

Initially, the protein with attached ATP in the Nterminal domain was selected for analyzing whether the ligand binds in the ATP binding site or not. The ligand was later removed using Chimera software. These docking results showed that gedunin successfully binds in the ATP binding pocket of the Hsp90 molecule at $\mathrm{N}$ terminal (Figure 4). Thus, the active conformation of the ligand and the best binding mode for the active site cavity were obtained. The conformation of the docked complex with the lowest binding energy values was selected and saved in pdb format. According to the docking results, gedunin exhibited a good average binding affinity $(-8.9 \mathrm{kcal} / \mathrm{mol})$ and interacted potentially with the amino acids within the binding pocket of the Hsp90 at its N-terminal.

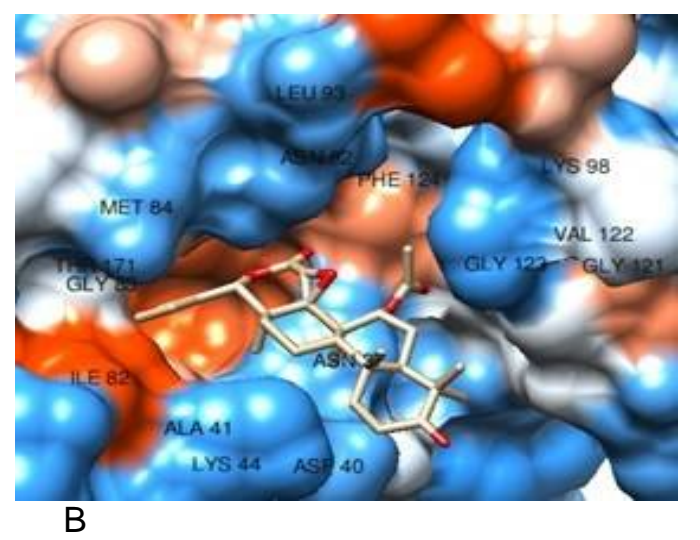

Figure 4: Three dimensional representation of the binding pocket. (A) Surface representation of the N-terminal ATP-binding site of Hsp90 with the bound ATP molecule (B) AutoDock predicted model of bound conformation of the compound gedunin at the ATP binding site of Hsp90 that demonstrated dengue antiviral activity in cell culture 


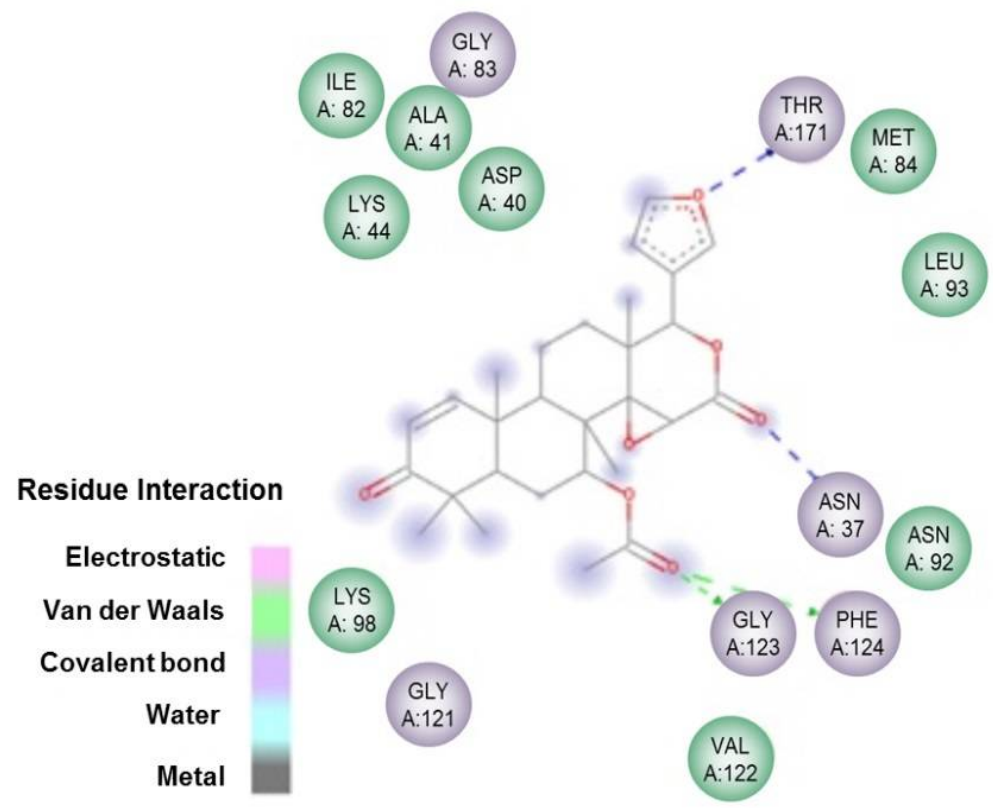

A

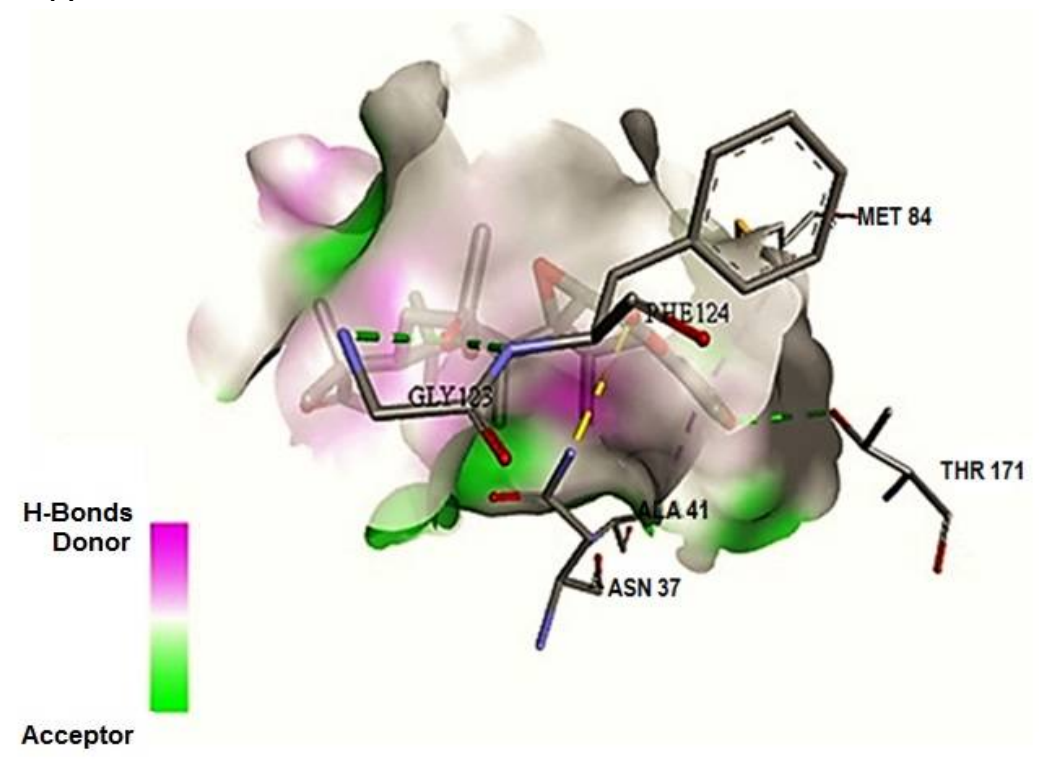

$B$

Figure 5: The interaction pattern of gedunin with the active site of host chaperone Hsp90 (PDB 1AM1) generated by the program, Discovery Studio 4.1.0. (A) Two dimensional interaction of the protein-ligand complex. The legend inset represents the type of interaction between the ligand atoms and the amino acid residues of the protein. (B) Three dimensional docking of the compound in the binding pocket showing the hydrogen bond interactions

The possible protein-inhibitor interactions of gedunin with the active site of Hsp90 molecule are shown in Figure 5A. Amino acid residues at the binding site interacting with the gedunin are Asn 37, Asp 40, Ala 41, Lys 44, Ile 82, Gly 83, Met 84, Asn 92, Leu 93, Lys 98, Gly 121, Val 122, Gly 123, Phe 124, and Thr 171. The compound also formed potential hydrogen bond interactions with the amino acids at the active site (Figure 5B). Amino acid residues involved in hydrogen bonding are Asn 37, Ala 41, Met 84, GLy 123, Phe 124, and Thr 171.

\section{DISCUSSION}

The aim of our work was to evaluate the antiviral property of the compound gedunin from the Indian neem plant against dengue virus and propose its potential mechanism of action through molecular docking studies. Gedunin has been shown to bind to the host chaperone machinery of Hsp90 and blocks its activity [14]. Hsp90s are host chaperone proteins which act as ATPases and consists of homodimeric 
complexes. Each monomer consists of a C terminal domain involved in dimerization, a middle domain and an N-terminal ATP binding domain [19]. Hsp90 plays important role in helping mutated proteins in several cancers. It is involved in stabilization of a number of oncogenic kinases, including HER2, EGFR, BCR-ABL, BRaf and EML4-ALK [20]. The host protein Hsp90 plays an essential role in the replication of various viruses, making it an important target for antiviral drugs. An antibiotic geldanamycin (GA), which was initially characterized as an anticancer agent, has been reported to exhibit broadspectrum antiviral activity in vitro against several viruses by targeting the ADP/ATP binding site of Hsp90 [21]. The target viruses include herpes simplex virus type-1 (HSV-1) [10], severe acute respiratory syndrome corona virus, vaccinia virus [23], influenza virus, vesicular stomatitis virus [22], hepatitis C virus [24] and ebola virus [11].

Gedunin, identified as HSP-90 inhibitor was therefore tested against the dengue replicon in vitro in BHK-15 cells. Development of subgenomic replicons of the virus offer great potential to study the replication process, as well as to study the effects of antiviral drugs/ inhibitors on the replication due to their noninfectious nature [25]. Different concentrations of the compound gedunin were tested against dengue virus replication using the DENV replicon, containing the reporter gene $(R$. luciferase) expressed in a replication dependent manner. It was observed that gedunin significantly reduced replication of dengue virus in cell culture. The exact mechanism of antiviral action of gedunin is not very clear yet. Several studies have shown that it inhibits the activity of the host chaperone Hsp90. Hsp90 has been believed to facilitate viral protein folding and activity of non-structural proteins such as polymerase, protease and helicase as well as the structural proteins [3]. The polymerase of several viruses require Hsp90 for genome replication which include influenza virus A [12], herpes simplex virus [26], flock house virus [27] and vesicular stomatitis virus and treatment with Hsp90 inhibitors such as geldanamycin and 17AAG lead to degradation of polymerase complexes [28,22].

Molecular docking analysis was then carried out using AutoDock vina software to evaluate the binding capability of gedunin with Hsp90 molecule and propose its possible mechanism of action. The obtained results suggested that the Hsp90 inhibitor gedunin directly binds in the $\mathrm{N}$ terminal ATP binding site of the protein and forms significant non-covalent and hydrogen bond interactions. In a study with geldanamycin, it was shown that the compound binds specifically in the ATP/ADP binding site of Hsp90 and inhibits the protein function. In a study conducted by Petrikaite and Matulis [7], they also suggested that the majority of Hsp90 inhibitors blocks ATPase activity of Hsp90 by binding in the $\mathrm{N}$-terminal ATP. These results correlate with the findings of the computational analysis of the inhibitor and the host chaperone in the current study. Recently, Hsp90 was shown to be an essential host protein for the replication of several negative strand RNA viruses [11]. Other studies have shown that host factors are involved in JEV life cycle and RNA virus replication and identified other host factors such as Hsp70 and GRP78 including Hsp90 in the secretion medium from JEV infected BHK-12 cells [29].

\section{CONCLUSION}

Using in vitro technique and molecular docking studies, a novel compound that inhibits DENV replication has been successfully identified. The findings of the study indicate that gedunin has a significant inhibitory activity against dengue virus in vitro and may prove to be a good lead compound for the development of an anti-dengue compound targeting the Hsp90 protein. Further investigations on the mechanism by which gedunin induce client protein degradation and inhibits dengue virus in vitro are required. Furthermore, the approach used in the present study may afford additional drug candidates for the development of therapies against dengue infections.

\section{DECLARATIONS}

\section{Acknowledgement}

This study was supported by the Higher Education Commission of Pakistan. We are thankful to Dr. Richard J Kuhn, Department of Biological Sciences, Purdue University for constant help and support and valuable discussions throughout the course of this investigation.

\section{Conflict of Interest}

No conflict of interest associated with this work.

\section{Contribution of Authors}

The authors declare that this work was done by the authors named in this article and all liabilities pertaining to claims relating to the content of this article will be borne by them. 


\section{Open Access}

This is an Open Access article that uses a funding model which does not charge readers or their institutions for access and distributed under the terms of the Creative Commons Attribution License (http://creativecommons.org/licenses/by/ 4.0) and the Budapest Open Access Initiative (http://www.budapestopenaccessinitiative.org/rea d), which permit unrestricted use, distribution, and reproduction in any medium, provided the original work is properly credited.

\section{REFERENCES}

1. Noble CG, Chen YL, Dong H, Gu G, Lim SP, Schul W, Wang QY, Shi PY. Strategies for development of dengue virus inhibitors. Antivir Res 2010; 85: 450-462.

2. Murrell S, Wu SC, Butler M. Review of dengue virus and development of a vaccine. Biotechnol Adv 2011; 29: 239-247.

3. Geller R, Taguwaa S, Frydman J. Broad action of Hsp90 as a host chaperone required for viral replication. Biochim Biophys Acta 2012; 1823: 698-706.

4. Wandinger SK, Richter K, Buchner J. The Hsp90 chaperone machinery. J Biol Chem 2008; 283: 1847318477.

5. Taipale M, Jarosz DF, Lindquist S. HSP90 at the hub of protein homeostasis: emerging mechanistic insights. Nat Rev Mol Cell Biol 2010; 11: 515-528.

6. McClellan AJ, Xia Y, Deutschbauer AM, Davis RW, Gerstein M, Frydman J. Diverse cellular functions of the Hsp90 molecular chaperone uncovered using systems approaches. Cell 2007; 131: 121-135.

7. Petrikaite $V$, Matulis $D$. Binding of natural and synthetic inhibitors to heat shock protein 90 and their clinical applications. Medicina (Kaunas) 2011; 47: 413-420.

8. Brandt GEL, Schmidt MD, Prisinzano TE, Blagg BSJ. Gedunin, a novel Hsp90 inhibitor: semisynthesis of derivatives and preliminary structure-activity relationships. J Med Chem 2008; 51: 6495-6502.

9. Jhaveri K, Taldone T, Modi S, Chiosis G. Advances in the clinical development of heat shock protein 90 (Hsp90) inhibitors in cancers. Biochim Biophys Acta 2012; 1823: 742-755.

10. Li YH, Tao PZ, Liu YZ, Jiang JD. Geldanamycin, a ligand of heat shock protein 90, inhibits the replication of herpes simplex virus type 1 in vitro. Antimicrob Agents Chemother 2004; 48: 867-872.

11. Smith DR, McCarthy S, Chrovian A, Olinger G, Stossel A, Geisbert TW, Hensley LE, Connor JH. Inhibition of heatshock protein 90 reduces Ebola virus replication. Antiviral Res 2010; 87: 187-194.

12. Naito $T$, Mamose $F$, Kawaguchi A, Nagata $K$. Involvement of Hsp90 in assembly and nuclear import of influenza virus RNA polymerase subunits. J Virol 2007; 81: 1339-1349.
13. Kamath SG, Chen $N$, Xiong $Y$, Wenhan R, Apte $S$, Humphrey M, Cragun J, Lancaster JM. Gedunin, a novel natural substance, inhibits ovarian cancer cell proliferation. Int J Gynecol Cancer 2009; 19: 1564-1569.

14. Patwardhan CA, Fauq A, Peterson LB, Miller C, Blagg $B S J$, Chadli $A$. Gedunin inactivates the co-chaperone p23 protein causing cancer cell death by apoptosis. $J$ Biol Chem 2013; 288: 7313-7325.

15. Bhowmik D, Chiranjib, Yadav J, Tripathi KK, Kumar KPS. Herbal remedies of Azadirachta indica and its medicinal application. J Chem Pharm Res 2010; 2: 62-72.

16. Kawaoka $Y$, Watanabe $S$, Hatta $Y$. Screen for inhibitors of filovirus and uses therefor, USPTO Application No. 20110253554, 27 October 2011.

17. Prodromou C, Roe SM, Brien RO, Ladbury JE, Piper PW, Pearl LH. Identification and structural characterization of the ATP/ADP-binding site in the Hsp90 molecular chaperone. Cell 1997; 90: 65-75.

18. Trott O, Olson AJ. AutoDock Vina: improving the speed and accuracy of docking with a new scoring function, efficient optimization and multithreading. J Comput Chem 2010; 31: 455-461.

19. Krukenberg KA, Street TO, Lavery LA, Agard DA. Conformational dynamics of the molecular chaperone Hsp90. Q Rev Biophys 2011; 44: 229-255.

20. Soga S, Akinaga S, Shiosu Y. Hsp90 inhibitors as anticancer agents, from basic discoveries to clinical development. Curr Pharm Des 2013; 19: 366-376.

21. Banerji $U$, Heat shock protein 90 as a drug target: some like hot. Clin Cancer Res 2009; 15: 9-14.

22. Chase G, Deng T, Fodor E, Leung BW, Mayer D, Schwemmle M, Brownlee G. Hsp90 inhibitors reduce influenza virus replication in cell culture. Virology 2008; 377: 431-439.

23. Hung JJ, Chung CS, Chang W. Molecular chaperone Hsp90 is important for vaccinia virus growth in cells. $J$ Virol 2002; 76: 1379-1390.

24. Nakagawa S, Umehara T, Matsuda $C$, Kuge S, Sudoh M, Kohara M. Hsp90 inhibitors suppress HCV replication in replicon cells and humanized liver mice. Biochem Biophys Res Commun 2007; 353: 882-888.

25. Noueiry AO, Olivo PD, Slomczynska U, Zhou Y, Buscher $B$, Geiss B, Engle M, Roth RM, Chung KM, Samuel M, Diamond MS. Identification of novel small-molecule inhibitors of West Nile virus infection. J Virol 2007; 81 : 11992-12004.

26. Burch $A D$, Weller SK. Nuclear sequestration of cellular chaperone and proteasomal machinery during herpes simplex virus type 1 infection. J Virol 2004; 78: 71757185.

27. Kampmueller KM, Miller DJ. The cellular chaperone heat shock protein 90 facilitates Flock House virus RNA replication in Drosophila cells. J Virol 2005; 79: 68276837.

28. Connor JH, McKenzie MO, Parks GD, Lyles DS. Antiviral activity and RNA polymerase degradation following Hsp90 inhibition in a range of negative strand viruses. Virology 2007; 362: 109-119.

Trop J Pharm Res, May 2017; 16(5): 1003 
Amraiz et al

29. Wu YP, Chang CM, Hung CY, Tsai MC, Schuyler SC, Wang RYL. Japanese encephalitis virus co-opts the ER- stress response protein GRP78 for viral infectivity. Virol J 2011; 8: 128. 